\title{
Low prevalence of Plasmodium falciparum parasites lacking pfhrp $2 / 3$ genes among asymptomatic and symptomatic school-age children in Kinshasa, Democratic Republic of Congo
}

\section{Sabin Nundu}

Nagasaki University

Hiroaki Arima

Nagasaki University

Shirley Simpson

Nagasaki University

Ben-Yeddy Abel Chitama

Nagasaki University

Yannick Bazitama Munyeku

Hokkaido University

Jean-Jaques Muyembe

Institut National de Recherche Biomédicale: Institut National de Recherche Biomedicale

Toshihiro Mita

Juntendo University

Stve Ahuka

Institut National de Recherche Biomédicale: Institut National de Recherche Biomedicale

Richard Culleton ( $\nabla$ culleton.richard.oe@ehime-u.ac.jp )

Ehime University https://orcid.org/0000-0001-8808-5771

\section{Taro Yamamoto}

Nagasaki University

\section{Research Article}

Keywords: Malaria, Rapid diagnostic tests, School-age children, Democratic Republic of Congo

Posted Date: November 5th, 2021

DOI: https://doi.org/10.21203/rs.3.rs-1052497/v1

License: (9) This work is licensed under a Creative Commons Attribution 4.0 International License.

Read Full License 
Version of Record: A version of this preprint was published at Malaria Journal on April 19th, 2022. See the published version at https://doi.org/10.1186/s12936-022-04153-2. 


\section{Abstract}

Background. Loss of efficacy of malaria diagnostic tests may lead to untreated or mistreated cases, compromising case management and control. There is an increasing reliance on rapid diagnostic tests (RDTs), with the most widely used of these targeting the Plasmodium falciparum histidine-rich protein 2 gene. There are numerous reports of the deletion of this gene in P. falciparum parasites in some populations, rendering them undetectable by PfHRP2 RDTs. We aimed to identify P. falciparum parasites lacking the P. falciparum histidine rich protein 2 and 3 genes isolated from asymptomatic and symptomatic school-age children in Kinshasa, Democratic Republic of Congo.

Methods. We assessed the performance of PfHRP2-based RDTs in comparison to microscopy and PCR. PCR was then used to identify parasite isolates lacking pfhrp2/3 genes.

Results. Of 462 DNA samples analysed, deletions of the pfhrp2 and pfhrp3 genes were found in only three $(2 \%)$ samples and one $(1 \%)$ sample in the RDT positive subgroup, respectively. No parasites lacking the pfhrp $2 / 3$ genes were found in the RDT negative subgroup.

Conclusion. Plasmodium falciparum histidine-rich protein 2/3 gene deletions are uncommon in the surveyed population, and do not result in diagnostic failure. We encourage the use of rigorous PCR methods to identify pfhrp $2 / 3$ gene deletions in order to minimize the overestimation of their prevalence.

\section{Introduction}

Despite concerted malaria control efforts, malaria remains a serious public health problem in the Democratic Republic of the Congo (DRC). The country accounted for $12 \%$ of all estimated malaria cases and $11 \%$ of deaths globally in 2019 (1). Malaria case management is based on rapid and accurate diagnosis and prompt treatment with effective antimalarial drugs (2).

The World Health Organization (WHO) recommends malaria diagnosis is performed by microscopy or with rapid diagnostic tests (RDTs) for all individuals presenting with malaria-like symptoms prior to the commencement of treatment (3). However, although microscopy is the gold standard for diagnosis (4), its use is challenging and subject to both false positive and negative results when performed by inexperienced microscopists, especially in the case of poor blood film preparation and when parasitemia is low (5-10). RDTs are frequently used as an alternative, especially in remote areas (11-14). In regions where $P$. falciparum is the most prevalent malaria parasite species, the most frequently used RDTs target $P$. falciparum histidine-rich protein-2 (PfHRP2). Sixty-four percent of all RDTs distributed by national malaria control programs worldwide in 2018 were of this type (15). Moreover, PfHRP2-based RDTs have better sensitivity $(16,17)$ and greater thermal stability $(18)$ than other RDTs $(17)$. Furthermore, numerous antibodies used to detect PfHRP2 also detect $P$. falciparum histidine-rich protein 3 (PfHRP3) as they have a high degree of similarity in their amino acid sequences $(19,20)$. However, the sensitivity of RDTs is dependent on the level of parasitaemia in the patient. Parasitemias lower than 200 per $\mu \mathrm{L}$ of blood may be associated with false negative results (21). Moreover, pfhrp2 and pfhrp3 ( $p$ fhrp2/3) may be deleted in 
some parasites rendering them undetectable by PfHRRP2-based RDTs (1). This loss of efficacy can lead to untreated or mistreated malaria cases, thus compromising malaria case management and control (17). Thus, the WHO recommends continuous nationwide surveillance of parasites harbouring $p f h r p 2 / 3$ deletions. It is recommended that if their prevalence exceeds $5 \%$, alternative RDTs should be used (1). In the DRC, the 2013-2014 nationwide demographic and health survey revealed a pfhrp2 gene deletion prevalence of $6.4 \%$ overall and $21.9 \%$ in Kinshasa among asymptomatic under five children (22). Interestingly, no pfhrp2/3 gene deletions were detected among symptomatic individuals (23). Munyeku et al (24), found an overall prevalence of $9.2 \%$ of parasites isolated from symptomatic malaria patients living Kwilu province, (near Kinshasa) carried Pfhrp2 gene deletions. However, only $9.9 \%$ of isolates that gave false negative PfHRP2-based RDTs results in that study carried pfhrp2 gene deletions, suggesting that the vast majority of RDT failures are not due to pfhrp2 gene deletions in that region.

This study aimed to assess the prevalence of $P$. falciparum parasites lacking the $p f h r p 2 / 3$ genes in isolates from asymptomatic and symptomatic school-age children in Kinshasa.

\section{Methods}

\section{Study design, Study area and Selection of participants}

Samples used in this study were collected from a previous cross-sectional survey carried out in MontNgafula-2 rural health zone (HZ) and Selembao urban $\mathrm{HZ}$ of Kinshasa, Democratic Republic of Congo (Fig. 1) (25).

Initially, 634 school-age children were enrolled in the study (427 asymptomatic and 207 symptomatic). DNA extraction, PfHRP2-based RDTs, microscopic examination and nested-PCR targeting the Plasmodium mitochondrial cytochrome c oxidase III (Cox3) were described in our previous study (25). Four hundred and sixty-two (266 asymptomatic and 196 symptomatic) pfcox3 PCR positive DNA samples were used in this study.

\section{Detection of P. falciparum infection \& selection of samples for pfhrp2/3 PCR}

We performed real-time PCR (qPCR) targeting the $P$. falciparum lactate dehydrogenase gene $(p f l d h)$ to quantify the number of parasite genomes per $\mu \mathrm{L}$ of extracted DNA solution from each of the samples using a serial dilution of laboratory cultured $P$. falciparum 3D7 strain DNA for calibration. The limit of detection of the pfhrp2 and pfhrp3 PCR assays used in this study was $1 \times 10^{-3} \mathrm{ng} / \mu \mathrm{L}$. In order to ensure that only samples with sufficient DNA for the amplification of pfhrp2 and pfhrp3 was used, only those samples with greater than $3 \times 10^{-3} \mathrm{ng} / \mu \mathrm{L}$ of DNA as determined by $p$ fldh qPCR were considered for further analysis (Table1) $(23,26)$. 
A calibration curve was prepared using the results of qPCR with control samples $(0.1 \mathrm{ng} / \mu \mathrm{L}, 0.01 \mathrm{ng} / \mu \mathrm{L}$, $0.001 \mathrm{ng} / \mu \mathrm{L}$ and $0.0001 / \mu \mathrm{L}$ ). Duplicated samples were loaded in 96-wells plates along with serially diluted positive controls (using gDNA extracted from cultured $P$. falciparum 3D7) as well as negative controls consisting of DNA samples from known malaria negative individuals (RDT-, microscopy- and PCR-) and distilled water for checking contamination. We repeated the assay for all discordant duplicates and counted three consistent results for confirmation. The DNA concentration of samples were quantified from each Ct values and the calibration curve.

\section{Detection of pfhrp $2 / 3$ gene deletions}

Pfhrp2 and pfhrp3 PCR genotyping was performed as previously described (26), with minor modifications using conventional single step PCR with primers targeting exon 2 of the genes. Genomic DNA from 3D7 (pfhrp2/3 positive), Dd2 (pfhrp2 negative) and HB3 (pfhrp3 negative) were used as controls. PCR products were visualized under UV light on $1.5 \%$ agarose gels run at 100 volts for 30 minutes and stained with Gel Red® solution (Biotium. California, USA) for 30 minutes.

\section{Statistical analyses}

Data was analysed using STATA version 14.2 (College Station. Texas, USA). Descriptive variables are presented as proportions (categorical variables) or median and interquartile range (continuous variables). Chi-square tests (or Fisher's exact tests when appropriate) were used to assess associations between categorical variables and $p f h r p 2 / 3$ gene deletion prevalence. Sensitivity (=true positive / (true positive + false negative) and specificity (=true negative / (true negative + false positive) of RDTs were calculated using PCR and microscopy as gold standard. Agreement between diagnostic techniques was assessed using Cohen's kappa coefficient. Using parasite densities, we assessed the sensitivity and the specificity of RDTs and microscopy at densities between 4 and 120 genomes/ $\mu \mathrm{L}$ of extracted DNA, and those greater than 120 genomes $/ \mu \mathrm{L}$ (assuming that a DNA concentration of $1 \times 10^{-4} \mathrm{ng} / \mu \mathrm{L}$ corresponds to four parasite genomes per $\mu \mathrm{L}(26))$. P-values of below 0.05 were considered significant.

\section{Results}

\section{Socio-demographic characteristics of the participants and malaria diagnosis}

We enrolled 462 school-age children, of which 266 were asymptomatic, and 196 were symptomatic. Of the 266 asymptomatic children, 136/266 (51\%) were female, 147/266 (55\%) were between the ages of 6 and 9 and 168/266 (63\%) lived in rural areas. Of the 196 symptomatic children, 94/196 (48\%) were female, 132/196 (67\%) were between the ages of 6 and 9 and 102/196 (52\%) lived in rural areas (Table 2). 


\section{Comparison of RDTs with PCR and Microscopy}

Among 266 DNA samples from asymptomatic children, 174/266 (65\%), 187/266 (70\%) and 130/266 (49\%) were PfHRP2_RDT, pfldh-qPCR and microscopy positive, respectively. The sensitivity and specificity of RDTs compared to PCR were 150/187 (80\%) and 55/79 (70\%) while the sensitivity and specificity of RDTs compared to microscopy were 119/130 (92\%) and 81/136 (60\%), respectively. Agreement between PfHRP2-based RDTs and PCR was moderate (Cohen's kappa $=0.48$ ) as was the agreement between pfhrp2-based RDTs and microscopy (Cohen's kappa $=0.51$ ) (Table 3 ).

Among 196 DNA samples from symptomatic infections, 131/196 (67\%), 171/196 (87\%) and 122/196 (62\%) were PfHRP2-based RDTs, pfldh-qPCR and microscopy positive, respectively. The sensitivity and specificity of RDTs compared to PCR were $128 / 171$ (75\%) and 22/25 (88\%) while sensitivity and specificity of RDTs compared to microscopy were 114/ 122 (93\%) and 57/74 (77\%), respectively. Findings showed satisfactory agreement between PfHRP2-based RDTs and microscopy (Cohen's kappa = 0.72) and fair agreement between PfHRP2-based RDTs and PCR (Cohen's kappa = 0.37) (Table 3).

\section{Performance of RDTS and microscopy examinations based on parasite densities}

We compared the sensitivity of RDTs and microscopy at lower limits of parasite density (<120 genomes/ $\mu \mathrm{L}$ ) and above ( $\geq 120$ genomes $/ \mu \mathrm{L})$. The sensitivity and specificity of RDTs were $96 \%$ (symptomatic: $93 \%$; asymptomatic: $100 \%$ ) and $37 \%$ (symptomatic: $55 \%$; asymptomatic: $31 \%$ ) while the sensitivity and specificity of microscopy were $91 \%$ (symptomatic: $90 \%$; asymptomatic: $94 \%$ ) and $59 \%$ (symptomatic: 65\%; asymptomatic: $56 \%$ ) (Table 4).

\section{Detection of Pfhrp2/3 gene deletions}

We used a conservative criterion for the detection of $p f h r p 2 / 3$ gene deletions through the selection of samples with DNA concentrations three times higher than the limit of detection of the pfhrp2/3 PCR assays. Of 462 DNA samples, 173 were selected for $p$ fhrp2/3 PCR analysis following $p$ fldh qPCR. Of the 173 isolates used for $p f h r p 2 / 3$ PCR, three were pfhrp2 negative and one was pfhrp3 negative (Fig. 2).

The overall prevalence of the pfhrp2 gene deletion was $2 \%$ (3/173) while it was $1 \%(1 / 173)$ for the pfhrp3 gene. All four samples that contained these mutant parasites had returned positive RDT results. Only 7 RDT negative samples had sufficient parasite densities for $p$ fhrp $2 / 3$ deletion, and none of these had pfhrp $2 / 3$ gene deletions. (Table 5) 


\section{Prevalence of $P$. falciparum hrp2/3 gene deletion by age, sex, health status and location}

Among the three samples that harbored pfhrp2 gene deletions, two were from children aged six to nine years, and all three were from female children, asymptomatic individuals and children living in the urban area. Age, sex, children health status and location were not associated to phhrp2/3 gene deletion (Table 6).

\section{Discussion}

Malaria rapid diagnostic tests play an important role in malaria case management and surveillance. Based on several reports that assess the prevalence of $p f h r p 2 / 3$ gene deletions, the WHO has recently recommended continuous surveillance of $P f h r p 2 / 3$-deleted $P$. falciparum $(17,27,28)$. This study used a rigorous method of DNA sample selection for evaluation of Pfhrp2/3-deleted $P$. falciparum $(23,26)$ which minimizes the overestimation of pfhrp2/3-deleted $P$. falciparum results by conventional approaches (22, 29,30 ). It is important to consider DNA quantity in samples subjected to PCR to identify pfhrp2/3 deletions, as low DNA levels may lead to false $p f h r p 2$-negative results and overestimation of the prevalence of pfhrp $2 / 3$ gene deletions.

We found three isolates harboring a pfhrp2 gene deletion and one isolate harboring a pfhrp3 gene deletion among pfhrp2-based RDT positive results. The sample harboring a pfhrp3 gene deletion was from a symptomatic child while the three samples harboring pfhrp2 gene deletions were from asymptomatic children. It has been shown that $p f h r p 2 / 3$-deleted parasites do not differ from wild-type parasites in their ability to cause malaria symptoms (31). Previous studies conducted in the DRC have found a pfhrp 2 gene deletion prevalence of $6.4 \%$ across the country and $21.9 \%$ in Kinshasa in a nationwide demographic and health survey among asymptomatic children (22) and $9.2 \%$ amongst symptomatic individuals in a neighboring province of Kinshasa (24). This difference may be explained by different methods used for the detection of Pfhrp $2 / 3$ deletions. Prior to our study, another study conducted in the DRC using a similar method of selection of samples with sufficient parasite isolates useful for the detection of Pfhrp2/3 gene deletions, did not find any isolates harboring pfhrp2/3deletions among symptomatic children (23) highlighting the fact that the method used in the previous large survey of asymptomatic parasite carriers (22) may have overestimated the prevalence of the pfhrp2 gene deletion.

Seven isolates were negative by RDT, but positive by qPCR with over $3 \times 10^{-3} \mathrm{ng}$ of parasite DNA per $\mu \mathrm{L}$ of extracted DNA solution. Five of these samples were negative by microscopy, suggesting relatively low parasitemia. RDT failure in these cases may be explained by data recording errors, operator-dependent and manufacturing quality (32-34) or by the presence of anti-pfhrp2 antibodies binding to the circulating 
antigens (35) or possibly due to the presence of mixed infection pfhrp2-negative and pfhrp2-positive parasites in the same isolates (36).

Among 196 isolates from symptomatic children, the sensitivity of PfHRP2-based RDTs compared to pfldh-qPCR was 75\%. Of 43 pfhrp2 RDT negative isolates when PCR was positive, 36 (84\%) had lower than 120 parasites genomes per $\mu \mathrm{L}$ of extracted DNA, and the highlight RDTs are less sensitive at low parasitemia as compared to PCR (21). This may exclude some symptomatic children from treatment (25)

Among 266 isolates from asymptomatic children, the sensitivity of PfHRP2-based RDTs compared to pfldh-qPCR was $82 \%$. All 37 RDT negative isolates when PCR was positive had below 120 parasite genomes per $\mu \mathrm{L}$ solution, and so highlight the importance of the use of PCR for the diagnosis of asymptomatic malaria parasite carriers $(25,37-41)$.

Although the samples used in this study did not represent a countrywide survey, the method used permitted minimization of the overestimation of the prevalence of $P$. falciparum parasites carrying pfhrp2/3-deletions which may occur with conventional methods.

\section{Conclusion}

The prevalence of $P$. falciparum parasites carrying deletions of the pfhrp $2 / 3$ gene is low in the population surveyed here, suggesting the use of PfHRP2-based RDTs remains appropriate for the detection of malaria in this region. We encourage the continuous use of rigorous PCR methods for the survey of pfhrp $2 / 3$ gene deletion prevalence.

\section{Declarations}

\section{Ethics approval and consent to participate}

The study was approved by the ethics committees of the School of Public Health, University of Kinshasa, DRC (Approval number: ESP/CE/042/2019) and the Institute of Tropical Medicine, Nagasaki University (Approval number: 190110208-2).

\section{Consent for publication}

All authors read and approved the final manuscript.

\section{Availability of data and materials}

The datasets used and/or analysed during the current study are available from 
the first author (SSN).

\section{Competing interests}

The authors declare that they have no competing interests.

\section{Funding}

This work was supported by the Japan International Cooperation Agency and the Joint Usage / Research Center on Tropical Disease, Institute of Tropical Medicine, Nagasaki University (2020-Ippan-14, 2020Ippan-23).

\section{Acknowledgments}

We thank the authorities of the Kinshasa Provincial Health Inspectorate and Institut National de Recherche Biomédicale (INRB) for facilitation. Special thanks and gratitude to Dr. Mamie Lau, the Head of Selembao Health Zone; Dr. Edo Molamba the Head of Mongafula-2 Health Zone as well as the Directors of the primary schools Ecole chretienne Edmond and Cité des aveugles for supervision. We thank Professor Osamu Kaneko for providing positive and negative controls and for his remarks and suggestions in the study design and procedures.

\section{Author contributions}

Conceptualization: SSN, TY, RC

Data curation: SSN, RC

Formal analysis: SSN, RC

Investigation: SSN, TY, HA

Methodology: SSN, RC, TY, TM

Contributed materials: RC, BYAC

Supervision: RC, TY, TM, DM, SA, JJM

\section{Writing-original draft: SNN}

Writing review \& editing: SSN, RC, TY, MT, SVS, HA, 
Laboratory works: SSN, SVS, HA, RC, BYAC

\section{References}

1. WHO. World Health Organization. World malaria report 2020. Geneva: World Health Organization; 2020 [cited 2021 September 13]. Available from:

https://www.who.int/publications/i/item/9789240015791.

2. WHO. World Health Organization. A global strategy for malaria control, 1993. Geneva: World Health Organization; 1993 [cited 2021 September 13]. Available from: https://apps.who.int/iris/bitstream/handle/10665/41785/9241561610.pdf? sequence=1\&isAllowed=y.

3. WHO Guidelines Approved by the Guidelines Review Committee. Guidelines for the Treatment of Malaria. Geneva: World Health Organization Copyright (c) World Health Organization, 2010;; 2010.

4. Maltha J, Gillet P, Jacobs J. Malaria rapid diagnostic tests in travel medicine. Clin Microbiol Infect. 2013;19(5):408-15.

5. McKenzie FE, Sirichaisinthop J, Miller RS, Gasser RA, Jr., Wongsrichanalai C. Dependence of malaria detection and species diagnosis by microscopy on parasite density. Am J Trop Med Hyg. 2003;69(4):372-6.

6. Stow NW, Torrens JK, Walker J. An assessment of the accuracy of clinical diagnosis, local microscopy and a rapid immunochromatographic card test in comparison with expert microscopy in the diagnosis of malaria in rural Kenya. Trans R Soc Trop Med Hyg. 1999;93(5):519-20.

7. Maguire JD, Lederman ER, Barcus MJ, O'Meara WA, Jordon RG, Duong S, et al. Production and validation of durable, high quality standardized malaria microscopy slides for teaching, testing and quality assurance during an era of declining diagnostic proficiency. Malar J. 2006;5:92.

8. Kilian AH, Metzger WG, Mutschelknauss EJ, Kabagambe G, Langi P, Korte R, et al. Reliability of malaria microscopy in epidemiological studies: results of quality control. Trop Med Int Health. 2000;5(1):3-8.

9. Muhindo HM, llombe G, Meya R, Mitashi PM, Kutekemeni A, Gasigwa D, et al. Accuracy of malaria rapid diagnosis test Optimal-IT(®) in Kinshasa, the Democratic Republic of Congo. Malar J. 2012;11:224.

10. Mwingira F, Genton B, Kabanywanyi AN, Felger I. Comparison of detection methods to estimate asexual Plasmodium falciparum parasite prevalence and gametocyte carriage in a community survey in Tanzania. Malar J. 2014;13:433.

11. Amoah LE, Abankwa J, Oppong A. Plasmodium falciparum histidine rich protein-2 diversity and the implications for PfHRP 2: based malaria rapid diagnostic tests in Ghana. Malar J. 2016;15:101. 
12. Maltha J, Gillet P, Bottieau E, Cnops L, van Esbroeck M, Jacobs J. Evaluation of a rapid diagnostic test (CareStart Malaria HRP-2/pLDH (Pf/pan) Combo Test) for the diagnosis of malaria in a reference setting. Malar J. 2010;9:171.

13. Rozelle JW, Korvah J, Wiah O, Kraemer J, Hirschhorn LR, Price MR, et al. Improvements in malaria testing and treatment after a national community health worker program in rural Liberia. Journal of Global Health Reports. 2021;5:e2021073.

14. Wurtz N, Fall B, Bui K, Pascual A, Fall M, Camara C, et al. Pfhrp2 and pfhrp3 polymorphisms in Plasmodium falciparum isolates from Dakar, Senegal: impact on rapid malaria diagnostic tests. Malar J. 2013;12:34.

15. WHO. World Health Organization. World malaria report 2019. Geneva: World Health Organization; 2019 [cited 2021 September 13]. Available from:

https://www.who.int/publications/i/item/9789241565721.

16. WHO. World Health Organization. Malaria Rapid Diagnostic Test Performance. Results of WHO product testing of RDTs: Round 8 (2016-2018) Geneva: World Health Organization; 2018 [cited 2021 November 3]. Available from:

https://apps.who.int/iris/bitstream/handle/10665/276190/9789241514965-eng.pdf.

17. WHO. World Health Organization. P. falciparum hrp2/3 gene deletions: conclusions and recommendations of a technical consultation Geneva: World Health Organization; 2016 [cited 2021 September 13]. Available from: https://www.who.int/malaria/mpac/mpac-sept2016-hrp2-consultationshort-report-session7.pdf.

18. Chiodini PL, Bowers K, Jorgensen P, Barnwell JW, Grady KK, Luchavez J, et al. The heat stability of Plasmodium lactate dehydrogenase-based and histidine-rich protein 2-based malaria rapid diagnostic tests. Trans R Soc Trop Med Hyg. 2007;101(4):331-7.

19. Lee N, Gatton ML, Pelecanos A, Bubb M, Gonzalez I, Bell D, et al. Identification of optimal epitopes for Plasmodium falciparum rapid diagnostic tests that target histidine-rich proteins 2 and 3 . J Clin Microbiol. 2012;50(4):1397-405.

20. Lee N, Baker J, Andrews KT, Gatton ML, Bell D, Cheng Q, et al. Effect of sequence variation in Plasmodium falciparum histidine- rich protein 2 on binding of specific monoclonal antibodies: Implications for rapid diagnostic tests for malaria. J Clin Microbiol. 2006;44(8):2773-8.

21. WHO. World Health Organization. Malaria rapid diagnostic test performance: results of WHO product testing of malaria RDTs: Round 5 (2013). Geneva: World Health Organization; 2013 [cited 2021 September 4]. Available from: https://www.who.int/publications/i/item/9789241507554. 
22. Parr JB, Verity R, Doctor SM, Janko M, Carey-Ewend K, Turman BJ, et al. Pfhrp2-Deleted Plasmodium falciparum Parasites in the Democratic Republic of the Congo: A National Cross-sectional Survey. J Infect Dis. 2017;216(1):36-44.

23. Parr JB, Kieto E, Phanzu F, Mansiangi P, Mwandagalirwa K, Mvuama N, et al. Analysis of falsenegative rapid diagnostic tests for symptomatic malaria in the Democratic Republic of the Congo. Sci Rep. 2021;11(1):6495.

24. Munyeku YB, Musaka AA, Ernest M, Smith C, Mansiangi PM, Culleton R. Prevalence of Plasmodium falciparum isolates lacking the histidine rich protein 2 gene among symptomatic malaria patients in Kwilu Province of the Democratic Republic of Congo. Infect Dis Poverty. 2021;10(1):77.

25. Nundu SS, Culleton R, Simpson SV, Arima H, Muyembe JJ, Mita T, et al. Malaria parasite species composition of Plasmodium infections among asymptomatic and symptomatic school-age children in rural and urban areas of Kinshasa, Democratic Republic of Congo. Malar J. 2021;20(1):389.

26. Parr JB, Anderson O, Juliano JJ, Meshnick SR. Streamlined, PCR-based testing for pfhrp2- and pfhrp3-negative Plasmodium falciparum. Malar J. 2018;17(1):137.

27. WHO. World Health Organization. False-negative RDT results and implications of new P. falciparum histidine-rich protein 2/3 gene deletions, 2016. Geneva: World Health Organization; 2016 [cited 2021 Septemeber 16]. Available from: https://apps.who.int/iris/bitstream/handle/10665/258972/WHOHTM-GMP-2017.18-eng.pdf;jsessionid=BA37E3E369DFA1098EAA29E4938FF6C3? sequence=1.

28. WHO. World Health Organization. Response plan to pfhrp2 gene deletions, 2019. Geneva: World Health Organization; 2019 [cited 2021 September 16]. Available from:

https://apps.who.int/iris/bitstream/handle/10665/325528/WHO-CDS-GMP-2019.02-eng.pdf.

29. Parr JB, Meshnick SR. Response to Woodrow and Fanello. J Infect Dis. 2017;216(4):503-4.

30. Woodrow CJ, Fanello C. Pfhrp2 Deletions in the Democratic Republic of Congo: Evidence of Absence, or Absence of Evidence? J Infect Dis. 2017;216(4):504-6.

31. Berhane A, Anderson K, Mihreteab S, Gresty K, Rogier E, Mohamed S, et al. Major Threat to Malaria Control Programs by Plasmodium falciparum Lacking Histidine-Rich Protein 2, Eritrea. Emerg Infect Dis. 2018;24(3):462-70.

32. WHO. World Health Organization. False-negative RDT results and implications of new reports of P. falciparum histidine-rich protein 2/3 gene deletions, 2017. Geneva: World Health Organization; 2017 [cited 2021 September 16]. Available from: https://apps.who.int/iris/bitstream/handle/10665/258972/WHOHTM-GMP-2017.18-eng.pdf;jsessionid=BA37E3E369DFA1098EAA29E4938FF6C3? sequence=1.

33. Watson OJ, Sumner KM, Janko M, Goel V, Winskill P, Slater HC, et al. False-negative malaria rapid diagnostic test results and their impact on community-based malaria surveys in sub-Saharan Africa. BMJ 
Glob Health. 2019;4(4):e001582.

34. Wu L, van den Hoogen LL, Slater H, Walker PG, Ghani AC, Drakeley CJ, et al. Comparison of diagnostics for the detection of asymptomatic Plasmodium falciparum infections to inform control and elimination strategies. Nature. 2015;528(7580):S86-93.

35. Ho MF, Baker J, Lee N, Luchavez J, Ariey F, Nhem S, et al. Circulating antibodies against Plasmodium falciparum histidine-rich proteins 2 interfere with antigen detection by rapid diagnostic tests. Malar J. 2014;13:480.

36. Pasquier G, Azoury V, Sasso M, Laroche L, Varlet-Marie E, Houzé S, et al. Rapid diagnostic tests failing to detect infections by Plasmodium falciparum encoding pfhrp2 and pfhrp3 genes in a nonendemic setting. Malar J. 2020;19(1):179.

37. Lo E, Zhou G, Oo W, Afrane Y, Githeko A, Yan G. Low parasitemia in submicroscopic infections significantly impacts malaria diagnostic sensitivity in the highlands of Western Kenya. PLoS One. 2015;10(3):e0121763.

38. Snounou G, Viriyakosol S, Jarra W, Thaithong S, Brown KN. Identification of the four human malaria parasite species in field samples by the polymerase chain reaction and detection of a high prevalence of mixed infections. Mol Biochem Parasitol. 1993;58(2):283-92.

39. Zaw MT, Thant M, Hlaing TM, Aung NZ, Thu M, Phumchuea K, et al. Asymptomatic and submicroscopic malaria infection in Kayah State, eastern Myanmar. Malar J. 2017;16(1):138.

40. Zainabadi K. Ultrasensitive Diagnostics for Low-Density Asymptomatic Plasmodium falciparum Infections in Low-Transmission Settings. J Clin Microbiol. 2021;59(4).

41. Doctor SM, Liu Y, Anderson OG, Whitesell AN, Mwandagalirwa MK, Muwonga J, et al. Low prevalence of Plasmodium malariae and Plasmodium ovale mono-infections among children in the Democratic Republic of the Congo: a population-based, cross-sectional study. Malar J. 2016;15:350.

\section{Tables}

Tables 1-6 are in the supplementary files section.

\section{Figures}



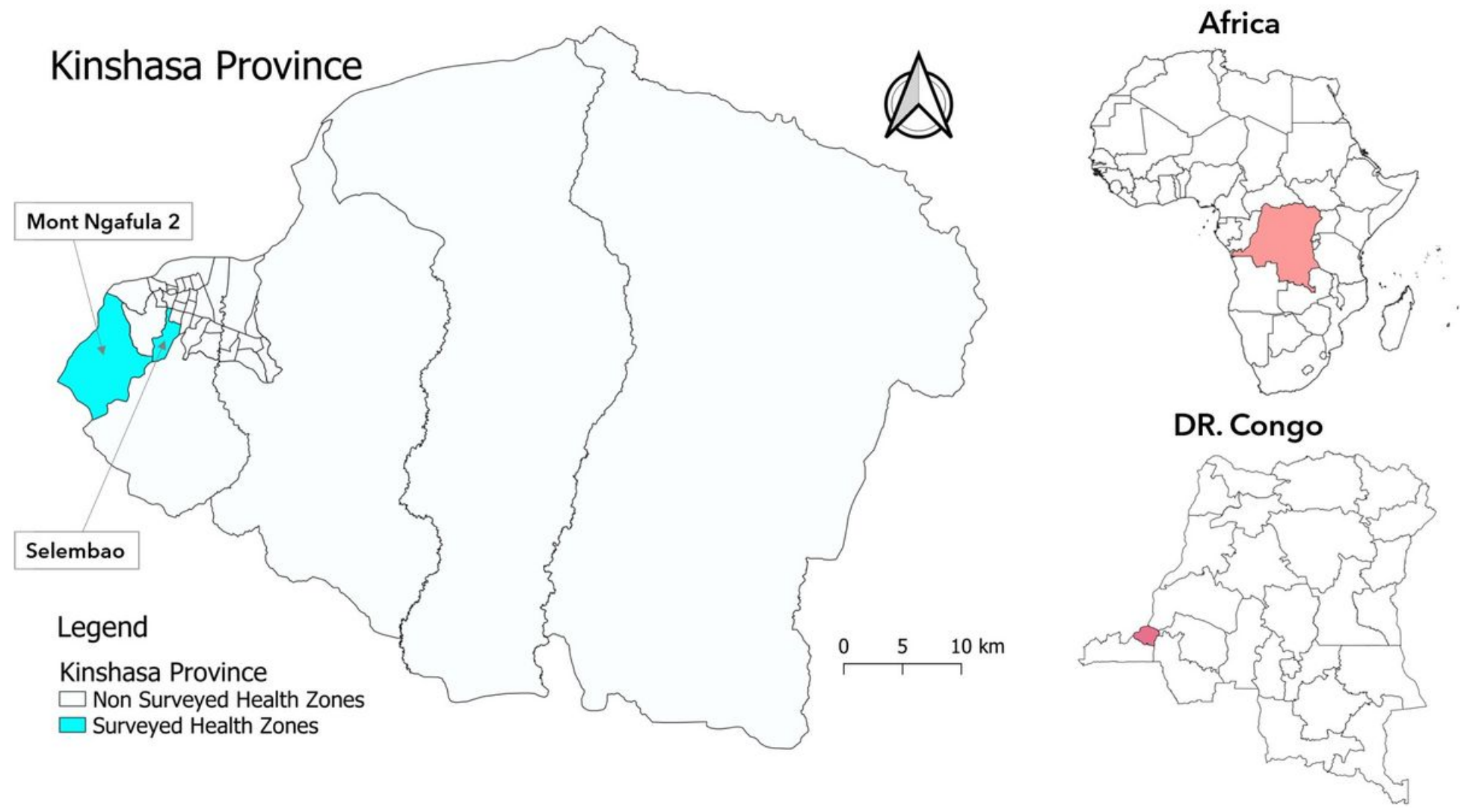

Figure 1

Sample collection sites 


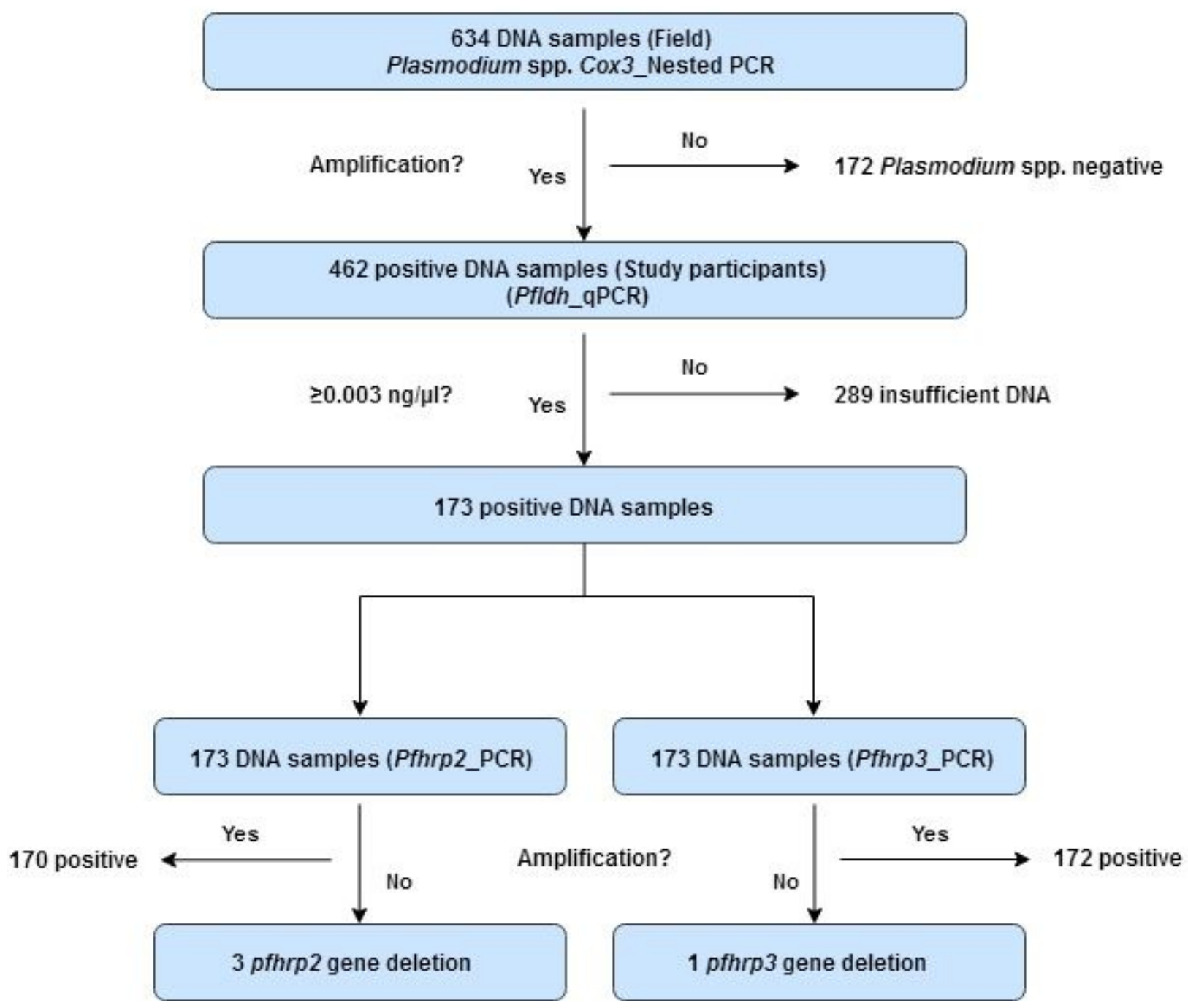

Figure 2

Assessment of pfhrp2/3 gene deletion

\section{Supplementary Files}

This is a list of supplementary files associated with this preprint. Click to download.

- Tables.docx 